\title{
The amounts of vitamin $A$ aldehyde, esters and alcohol and of carotenoids in hen's eggs and in day-old chicks
}

\author{
By P. A. PLACK \\ Unit for Biochemical Research bearing on Fisheries' Problems,* \\ National Institute for Research in Dairying, Shinfield, Reading \\ (Received 27 August 1962-Revised 10 October 1962)
}

In the ripe eggs of several species of marine and freshwater teleost fish, the predominant form of vitamin $A$ is the aldehyde (Plack \& Kon, 196r; Plack, Woodhead \& Woodhead, I96r). Vitamin A aldehyde has also been found in the megalecithal eggs of other vertebrates, and in particular in those of the domestic hen (Plack, 1960; Plack \& Kon, I96r). Since the aldehyde may be of importance in embryonic development, the amounts of vitamin $A$ aldehyde in eggs and in day-old chicks have been compared, and it has been found that only $16 \%$ of the aldehyde assumed to be present originally in the egg is present in the day-old chick. Results for vitamin A esters and alcohol and for carotenoids are also given, though similar results have been reported previously (Parrish, Williams, Hughes \& Payne, I950; Parrish, Williams \& Sanford, I95 I). The effect of 2 I days' incubation on the vitamin $A$ and carotenoid contents of infertile eggs was also studied.

\section{EXPERIMENTAL}

Animals. The six Light Sussex hens, A-F, described in the previous paper (Plack, I963) were used. Eggs collected on the 5 th, 6th, 12th and $13^{\text {th }}$ days of the initial I5-day period, when the hens received a breeder's mash containing maize and dried grass and $2.5 \mathrm{mg}$ added vitamin $\mathrm{A} / \mathrm{kg}$ but no vitamin A separately by mouth, were kept for setting. Further eggs, collected on the 26 th and $27^{\text {th }}$ days during the second period, when the hens received Io $\mathrm{mg}$ vitamin A/day by mouth, were also kept and set separately. Between the collection of eggs and their incubation there were periods of 13 or 6 days for the first group and 6 days for the second group, during which time the eggs were kept at room temperature and turned daily. All the eggs were fertile and developed to some extent. Out of the seventeen from the initial period in which the hens were not dosed with vitamin $A$, thirteen chicks hatched, as did six chicks out of seven eggs from the period when the supplement was given.

To study the effect of $2 \mathrm{I}$ days' incubation on infertile eggs, another two Light Sussex hens, $\mathrm{G}$ and $\mathrm{H}$, were used. They were kept in single battery cages on a diet of breeder's mash containing maize and dried grass and $2.5 \mathrm{mg}$ added vitamin $\mathrm{A} / \mathrm{kg}$, but received no vitamin A separately by mouth. When each bird had laid at least three eggs, three eggs from each were analysed. Next, three eggs were similarly obtained from each bird, incubated for 21 days and analysed. Finally, three eggs again from each bird were analysed directly. The whole procedure of collection took 18 days.

* Grant-aided by the Development Fund. 
Between the time of collection and analysis, or incubation, there were periods of up to 4 days during which the eggs were kept at room temperature.

Chemicals. A.R. grade chemicals were used as supplied, with the exceptions mentioned by Plack (1963).

Extraction of vitamin $A$ and carotenoids from chicks. The chicks were killed by breaking their necks and homogenized with $100 \mathrm{ml}$ water in a blender (Atomix; Measuring and Scientific Equipment Ltd) under nitrogen, and the contents of the blender were transferred to a polythene bottle, with washings, and freeze-dried overnight. Since it was convenient to carry out the analyses in groups of six, only twelve of the thirteen chicks from the first group and all six from the second group were analysed. Two methods of extraction were used, method I for six of the twelve chicks in the first group and for the six in the second and method 2 for the remaining six chicks of the first group.

Method I : the dry material was extracted in a Soxhlet apparatus with diethyl ether, and the solid residue remaining in the thimble was further extracted with light petroleum (b.p. 40-60\%) in the presence of ethanol, as described by Plack ( 1963 ), except that Soxhlet extraction was carried on for $6 \mathrm{~h}$ and the light-petroleum extract was filtered through a cotton-wool plug to remove small feathers.

Method 2: the freeze-dried material was extracted directly in a blender under nitrogen with three lots of $200 \mathrm{ml}$ light petroleum after the addition of $30 \mathrm{ml}$ water and $60 \mathrm{ml}$ ethanol. The extracts were combined and filtered through a cotton-wool plug to remove small feathers, the solvent was removed and the residue dissolved in $\mathrm{n}$ hexane, and the volume was made to $30 \mathrm{ml}$ with the same solvent.

Extraction of vitamin $A$ and carotenoids from eggs. The method described by Plack (1963) was used except that, with the incubated infertile eggs, both the yolk and white were freeze-dried and extracted, since separation of the yolk might have resulted in rupture of the weakened yolk membrane and loss of yolk. There is no vitamin $A$ in egg white (Plack, I960).

Determination of vitamin $A$ and carotenoids. Vitamin $A$ aldehyde was measured, as described by Plack ( 1963 ), in the light-petroleum extract and, after mild saponification (see Plack \& Kon, 196I), in the diethyl ether extract obtained by extraction method $\mathrm{I}$. The light-petroleum extract from method 2 was subjected to mild saponification before determination of the aldehyde. For the second group of chicks, vitamin A aldehyde was determined in the light-petroleum extract and in the combined extract obtained by mixing one-quarter of the light-petroleum and one-quarter of the diethyl ether extracts. In general, one-half of the total volume of these extracts was used for determination of aldehyde, but with the unsaponified light-petroleum extracts a maximum of $0.5 \mathrm{~g}$ lipid was used.

When values for the light-petroleum and diethyl ether extracts were obtained, the sum of the two results was used as the content of vitamin A aldehyde; when values for the light-petroleum and combined extracts were available, the higher value was used (see p. 247).

Vitamin A esters and alcohol and carotenoids were determined as described previously (Plack, I963). 
Comparison of values for eggs with those for chicks. For the first group of chicks, from eggs laid by the hens when they were not dosed with vitamin A, mean values for the eggs laid by each hen and analysed during this 15 -day period were used (see Plack, 1963). The values for contents of vitamin A aldehyde, esters, alcohol, esters + alcohol and aldehyde + esters + alcohol and carotenoids in each chick were then expressed as percentages of the corresponding mean values for the eggs laid by the same hen. In this way, differences between hens were reduced, and the results for the twelve chicks from six hens could be combined.

For the second group of chicks, from eggs laid by the hens when they were receiving Io $\mathrm{mg}$ vitamin $\mathrm{A} /$ day, estimated values for the eggs set were obtained by plotting values for individual eggs analysed against date of laying, for each hen, and reading off the appropriate values. The values for individual chicks were then expressed as percentages of the estimated values for eggs, and the results were combined as before.

\section{RESULTS}

There was some variation between the values obtained for chicks from eggs laid by the different hens; however, to give a general picture of the vitamin A content of day-old chicks, mean values are shown in Table $I$ for twelve chicks from eggs laid by the six hens during the period when they were not being dosed with vitamin $A$. These values may be compared with similar values for eggs laid during the same period given by Plack (1963). In Table 1 there are also given mean values for six chicks from eggs laid by four of the hens when they were receiving Io $\mathrm{mg}$ vitamin $\mathrm{A} /$ day. Of the other two hens, one was moulting and laying eggs infrequently and the other laid no eggs on the 2 days when eggs were collected for setting. This second group of chicks contained considerably more vitamin A aldehyde and esters, slightly more vitamin A alcohol and less carotenoids than the first.

Table I. Mean values and ranges for weights of eggs and for amounts of vitamin $A$ aldehyde, esters and alcohol and of carotenoids in day-old chicks from hens on a diet of breeder's mash receiving either no additional vitamin $A$ or 1o $m g$ vitamin $A /$ day

\begin{tabular}{|c|c|c|c|c|}
\hline & \multicolumn{2}{|c|}{$\begin{array}{c}\text { Chicks from eggs laid by } \\
\text { undosed hens }\end{array}$} & \multicolumn{2}{|c|}{$\begin{array}{l}\text { Chicks from eggs laid by } \\
\text { dosed hens }\end{array}$} \\
\hline & Value & Range & Value & Range \\
\hline No. of chicks & 12 & - & 6 & - \\
\hline Hens & $A-F^{*}$ & 一 & $A, D, E, F *$ & - \\
\hline Weight of eggs before incubation (g) & $64 \cdot 1$ & $57 \cdot 5-70 \cdot 1$ & $62 \cdot 6$ & $6 r \cdot 0-63 \cdot 6$ \\
\hline Vitamin $\mathrm{A}$ aldehyde $(\mu \mathrm{g})$ & 3.8 & $I \cdot 7-7 \cdot 1$ & $10 \cdot 1$ & $5 \cdot 1-18 \cdot 3$ \\
\hline Vitamin A esters ( $\mu \mathrm{g})$ & $67 \cdot 6$ & $45 \cdot 4-80 \cdot 6$ & 165 & I $15-197$ \\
\hline Vitamin A alcohol $(\mu \mathrm{g})$ & $2 \mathrm{I} \cdot 4$ & $16 \cdot 2-27 \cdot 0$ & $26 \cdot 5$ & $20 \cdot 7-33 \cdot 3$ \\
\hline Carotenoids $(\mu \mathrm{g})$ & $35^{8}$ & $307-420$ & 263 & $202-326$ \\
\hline
\end{tabular}

The values for individual chicks have been compared with mean values, obtained as described above for eggs laid by their mothers. The mean values obtained from these individual values are given in Table 2. It will be seen that from egg to chick the 
contents of both vitamin $\mathrm{A}$ aldehyde and vitamin $\mathrm{A}$ alcohol decreased to about $16 \%$ of the original value and that of carotenoids to $76 \%$. The content of vitamin A esters increased to $270 \%$ in the chicks from eggs laid by the hens when they were not dosed with vitamin $\mathrm{A}$, but the percentage increase was smaller for the chicks from eggs laid by the dosed hens. About $40 \%$ of the estimated total vitamin A in the egg was not recovered in the day-old chick.

Table 2. Mean values and ranges for amounts of vitamin $A$ aldehyde, esters and alcohol and of carotenoids in day-old chicks, expressed as percentages of the mean values for eggs laid by the mother hens

(For the first group of chicks, mean values for the eggs laid by each hen during 15 days have been taken as $100 \%$. For the second group, egg values have been obtained from graphs for individual hens of the values for eggs laid before and after the eggs taken for setting plotted against date of laying (see Plack, r 963 ). Mean values for the two groups of chicks have then been taken. Twelve chicks in the first group, six in the second)

\begin{tabular}{|c|c|c|c|c|}
\hline \multirow[b]{2}{*}{ Component } & \multicolumn{2}{|c|}{$\begin{array}{l}\text { Chicks from eggs laid } \\
\text { by undosed hens }\end{array}$} & \multicolumn{2}{|c|}{$\begin{array}{l}\text { Chicks from eggs laid } \\
\text { by dosed hens* }\end{array}$} \\
\hline & Value & Range & Value & Range \\
\hline yde & $16 t$ & $9-28$ & 16 & $6-24$ \\
\hline hol & $\begin{array}{r}270 \\
18 \\
76\end{array}$ & $\begin{array}{c}203-364 \\
13-21 \\
63-85\end{array}$ & $\begin{array}{r}177 \\
16 \\
76\end{array}$ & $\begin{array}{l}142-226 \\
11-22 \\
63-92\end{array}$ \\
\hline $\begin{array}{l}\text { s +alcohol } \\
\text { yde + esters + alcohol }\end{array}$ & $\begin{array}{l}62 \\
56 \dagger\end{array}$ & $\begin{array}{l}53-72 \\
48-63\end{array}$ & $\begin{array}{l}72 \\
61\end{array}$ & $\begin{array}{l}53-86 \\
47-69\end{array}$ \\
\hline
\end{tabular}

Vitamin A aldehyde

Vitamin A esters

Vitamin A alcohol

Carotenoids

Vitamin A esters + alcohol

Vitamin $\mathrm{A}$ aldehyde + esters + alcohol

* $10 \mathrm{mg}$ vitamin $\mathrm{A} /$ day by mouth.

$\dagger$ Mean value for eleven chicks.

Table 3. Amounts ( $\mu \mathrm{g} / \mathrm{egg}$ ) of vitamin $A$ aldehyde, esters and alcohol and of carotenoids in fresh and incubated infertile hen's eggs

(Three eggs in each group. Fresh $I$ and fresh 2 indicate the groups of eggs laid before and after the group taken for incubation)

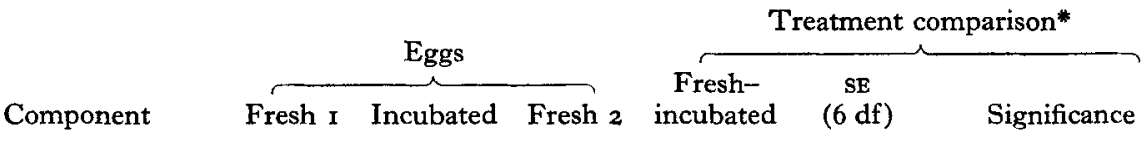

\begin{tabular}{|c|c|c|c|c|c|c|}
\hline \multirow[b]{2}{*}{ Vitamin A aldehyde } & & \multirow[b]{2}{*}{$x \cdot 46$} & \multirow[b]{2}{*}{$0.05>P>0.01$} \\
\hline & $18 \cdot 3$ & I6.I & $21 \cdot 8$ & 4.0 & & \\
\hline Vitamin A esters & $14^{\circ} \mathrm{I}$ & $19 \cdot 3$ & $16 \cdot 6$ & $-4 \cdot 0$ & 0.66 & $0.001>P$ \\
\hline Vitamin A alcohol & $103 \cdot 2$ & $76 \cdot 7$ & $103 \cdot 0$ & $26 \cdot 4$ & $2 \cdot 24$ & $0.001>P$ \\
\hline Carotenoids & 322 & 264 & 302 & 48 & 6.9 & $0.001>P$ \\
\hline $\begin{array}{l}\text { Vitamin A aldehyde }+ \\
\text { esters }+ \text { alcohol }\end{array}$ & $135^{\circ} 6$ & I I $2 \cdot 1$ & $141^{\circ} 4$ & $26 \cdot 4$ & $2 \cdot 80$ & $0.001>P$ \\
\hline & & & Hen $\mathbf{H}$ & & & \\
\hline Vitamin $A$ aldehyde & 16.6 & I $5 \cdot 8$ & $17 \cdot 6$ & $x \cdot 3$ & $\mathrm{I} \cdot 84$ & $P>0.10$ \\
\hline Vitamin A esters & $17 \cdot 3$ & $25 \cdot 4$ & $20 \cdot 6$ & $-6 \cdot 4$ & $\mathbf{I} \cdot 27$ & $0.01>P>0.001$ \\
\hline Vitamin A alcohol & 98.7 & 84.0 & I I 9.0 & $24 \cdot 8$ & $2 \cdot 84$ & $0.00 \mathrm{I}>P$ \\
\hline Carotenoids & 417 & 353 & $3^{88}$ & 50 & $14 \cdot 8$ & $0.05>P>0.01$ \\
\hline $\begin{array}{l}\text { Vitamin A aldehyde }+ \\
\text { esters }+ \text { alcohol }\end{array}$ & $132 \cdot 6$ & $125 \cdot 2$ & $157 \cdot 2$ & $19 \cdot 6$ & $4 \cdot 42$ & $0.01>P>0.001$ \\
\hline
\end{tabular}

* Standard errors and significance of treatment comparisons based on within-period variation (see p. 247). 
Since these changes might have occurred with incubated infertile eggs and might be unconnected with the development of the chick, a control experiment was carried out. The differences were not so clear as those between eggs and chicks, and a statistical analysis of the results is given in Table 3 . Because the eggs chosen for incubation were always second-period eggs, the effect of incubation is confounded with any curvature there may be in the time trends (some differences between the two groups of fresh eggs were significant for particular, and different, observations made on the eggs of the two hens) and the calculation of the standard errors in Table 3 from the within-period variations is not strictly valid. Nevertheless the standard errors are included as a rough guide to the significance of the treatment difference. With hen $\mathrm{G}$, there was an apparently significant decrease $(0.05>P>0.0 x)$ in aldehyde content after incubation to $80 \%$ of the content in fresh eggs, but with hen $\mathrm{H}$ the decrease to $92 \%$ was not significant. For the other substances the two birds responded similarly, and the changes appeared to be significant. Mean values, for the two birds, for incubated eggs, expressed as percentages of the mean values for fresh eggs laid before and after those taken for incubation, are given in Table 4 .

Table 4. Amounts of vitamin $A$ aldehyde, esters and alcohol and of carotenoids in incubated infertile eggs expressed as percentages of those in fresh infertile eggs, and amounts in day-old chicks expressed as percentages of those in eggs from the same hens

(Mean values taken from Table 3 for the term (incubated $\times 2 \times 100) \div($ fresh $x+$ fresh 2 ) for hens $G$ and $H$, and values taken from Table 2 for chicks from eggs laid by hens not dosed with vitamin A)

$\begin{array}{lcc}\text { Component } & \begin{array}{c}\text { Infertile } \\ \text { eggs }\end{array} & \begin{array}{c}\text { Day-old } \\ \text { chicks }\end{array} \\ \text { Vitamin A aldehyde } & 86^{*} & 16 \\ \text { Vitamin A esters } & 130 & 270 \\ \text { Vitamin A alcohol } & 75 & 18 \\ \text { Carotenoids } & 86 & 76 \\ \text { Vitamin A aldehyde+esters + alcohol } & 84 & 56\end{array}$

* The difference for hen $G$ appeared to be significant, but that for hen $\mathrm{H}$ was not significant (see Table 3).

\section{DISCUSSION}

The low values for vitamin A aldehyde have made the determination of this compound more complicated in chicks than in eggs. Extraction with diethyl ether removed from eggs an amount of aldehyde so small that, although an extinction reading at the appropriate wavelength was obtained, the colour in the Carr-Price test appeared yellow instead of blue. When calculated for the whole egg the quantity of the substance possibly vitamin A aldehyde was about I $\mu \mathrm{g}$ which, in comparison with some $20 \mu \mathrm{g}$ vitamin A aldehyde found in the light-petroleum extract of eggs, is negligible. It was so with fresh fertile eggs and with the fresh and incubated infertile eggs, and values for vitamin $A$ aldehyde in the diethyl ether extracts from eggs have not been included.

With chicks, the low content of vitamin A aldehyde in the light-petroleum extracts made it necessary to examine the diethyl ether extracts in case the vitamin $A$ aldehyde linkage to protein or lipid had changed and altered the behaviour of the aldehyde on 
extraction. As with eggs, the amount of aldehyde in the diethyl ether extract was of the order of $\mathrm{I} \mu \mathrm{g} / \mathrm{chick}$. In comparison with the $2-3 \mu \mathrm{g} /$ chick present in the lightpetroleum extract, this amount was significant, although the substance was not unequivocally identified as vitamin A aldehyde. With this method of extraction (method I) and analysis, two low values were obtained, and they were added to give the total vitamin A aldehyde.

With method 2, involving a light-petroleum extraction only, the aldehyde was determined after mild saponification; thus, although the summation of two errors in estimating two small amounts of aldehyde was avoided, there was a loss of some $20 \%$ of the aldehyde on saponification (see Plack \& Kon, I96I). When chicks from the same hen were compared, method 2 gave three higher values for aldehyde than method I and two lower values.

With the second batch of chicks, a further modification was introduced. After extraction by method I, vitamin A aldehyde was determined in the light-petroleum extract and in the combined light-petroleum and diethyl ether extracts after mild saponification. With the combined extract, there were two factors, the additional vitamin A aldehyde from the diethyl ether extract and the loss of some $20 \%$ of the total aldehyde by the saponification procedure. As might be expected, with low values for vitamin $A$ aldehyde the value obtained with the combined extract was higher than that with the light-petroleum extract, and with the higher values for aldehyde the reverse obtained. The higher of the two values was used.

The aforesaid implies that there was some uncertainty about the low values for vitamin A aldehyde in chicks; however, when they are considered as percentages of the aldehyde present in fresh eggs, even large errors leave the general picture substantially unchanged. Nevertheless, for concentrations of vitamin A aldehyde lower than $0.5 \mu \mathrm{g} / \mathrm{g}$ tissue, an improved method of determination would be useful.

From the values in Table $\mathrm{I}$, vitamin $\mathrm{A}$ esters comprised 73 and $82 \%$ of the total vitamin $\mathrm{A}$ in the two groups of chicks, whereas in eggs vitamin A alcohol is the predominant form (Neff, Parrish, Hughes \& Payne, I949). These findings are in agreement with those of Parrish et al. (I95I).

The changes between egg and chick in the various substances determined are given in Table 2. For this comparison it was deemed preferable to take mean values for eggs laid over a period of time by each hen, but with the second group of chicks from eggs laid by hens receiving $10 \mathrm{mg}$ vitamin $\mathrm{A} /$ day this procedure could not be applied, since the content of vitamin A was rising throughout the period. The method of plotting values for each egg against date of laying and interpolating values for the eggs set was therefore used. For the two groups of chicks, the percentage changes from egg to chick were very similar, with the exception of the values for vitamin A esters, vitamin A esters + alcohol and vitamin A aldehyde+esters + alcohol. This discrepancy was due to the increase in the ratio of vitamin A esters to alcohol in the eggs; in the first period (without dosing) the ratio was about $0.2 \mathrm{I}$, and in the period during which the hens received to $\mathrm{mg}$ vitamin $\mathrm{A} /$ day, as vitamin A palmitate, it increased to $0.4-0.7$ (see Plack, 1963).

Vitamin A aldehyde, whose amount in the chick was $16 \%$ of that in the egg, might 
have been converted into vitamin $A$ alcohol or esters or could have been used in some developmental process or merely broken down. Its fate cannot be decided from the findings presented here. In an earlier experiment (Plack, unpublished observation) most of the aldehyde remaining in a chick was found to be in the unabsorbed yolk.

The only function of vitamin A definable in chemical terms is in the visual cycle, in which the active form is the II-cis isomer of vitamin A aldehyde combined with a protein to form a visual pigment. It is possible that some of the aldehyde present in the egg passes into the eyes of the chick, but the quantity present in the egg is many times that present in the eyes of animals larger than the chick, and the eye is thought to obtain its supply of aldehyde by oxidation and isomerization of the vitamin A alcohol circulating in the blood.

Vitamin A aldehyde has recently been found in the blood of laying hens (Plack, unpublished observation) and also in their livers (Plack, 1963). In hen's blood plasma, $10-15 \%$ of the total vitamin A may be present as the aldehyde, whereas in the liver the aldehyde constitutes less than I \% of the total. The proportions of vitamin A aldehyde, esters and alcohol in hen's blood plasma are similar to those in eggs, and the transfer of vitamin $\mathrm{A}$ from the one to the other may be merely a passive process. The developing chick embryo changes the proportions of the three forms of vitamin A found in the egg, so that the ester form predominates in its liver store and in the unabsorbed yolk (Parrish et al. 1951), whereas in the egg vitamin A alcohol is predominant (Neff et al. 1949). The values in Table $\mathrm{I}$, and those for the corresponding eggs from hens not dosed with vitamin A (Plack, 1963), also show that the amounts of vitamin A esters in the chick were greater than those present in the egg, and the decrease in the amounts of vitamin A alcohol from egg to chick would amply account for the increased quantity of vitamin A esters. It is possible that some of the vitamin $A$ aldehyde present in the egg suffered a similar transformation into the alcohol or ester form of vitamin $\mathrm{A}$; with the liver again the predominant store of vitamin $\mathrm{A}$ in the chick, the percentage of the aldehyde form of vitamin A present in it might be expected to be low. The loss of vitamin A from egg to chick, some $40 \%$ of the total vitamin $\mathrm{A}$, precludes calculation of the amount of aldehyde that might be transformed in this way.

The values in Table 2 must be considered in conjunction with those showing changes occurring on incubation of infertile eggs (Table 4). For this purpose it is assumed that there is no significant difference between the vitamin $\mathbf{A}$ and carotenoid contents of fertile and infertile hens' eggs and that incubated infertile eggs are an adequate control for the effects of incubation not attributable to development of the chick. Table 4 shows that with incubated infertile eggs the changes in vitamin A content were similar to, though much less marked than, those between chicks and eggs from hens receiving no additional vitamin $\mathrm{A}$ by mouth; the changes in carotenoid content, however, were closer. This control experiment indicates also that, although some changes in the vitamin A and carotenoid contents of eggs may have taken place while eggs for setting were held at room temperature until incubated, such changes were not of the same order as those from eggs to chicks. The major part of the changes shown in Table 2 may therefore be attributed to the development of the chick. 
Further experiments are needed to show whether the fall in vitamin A aldehyde content from egg to chick indicates that it is of importance in embryonic development.

\section{SUMMARY}

I. The amounts of vitamin A aldehyde, esters and alcohol and of carotenoids in day-old chicks from eggs laid by hens receiving a breeder's mash but no additional vitamin $\mathrm{A}$ by mouth, and by hens receiving the breeder's mash and Io $\mathrm{mg}$ vitamin $\mathrm{A} /$ day by mouth, have been determined. These values have been compared with similar values for eggs from the same hens.

2. The corresponding differences between infertile eggs incubated for 21 days and fresh infertile eggs have been determined.

3. Day-old chicks from eggs laid by hens not dosed with vitamin A contained $16 \%$ of the vitamin A aldehyde, $270 \%$ of the vitamin A esters, $18 \%$ of the vitamin A alcohol, $56 \%$ of the vitamin A aldehyde + esters + alcohol and $76 \%$ of the carotenoids present in eggs laid by their mothers. Corresponding values for chicks from eggs laid by the dosed hens were $16, \mathrm{I} 77, \mathrm{I} 6,6 \mathrm{I}$ and $76 \%$ and for the incubated infertile eggs $86,130,75,84$ and $86 \%$ for vitamin A aldehyde, esters, alcohol, aldehyde + esters + alcohol and carotenoids, respectively.

4. Some conversion of vitamin A alcohol into vitamin A esters occurred during the development of the chick, but it was not possible to establish whether most of the vitamin A aldehyde present in the egg was converted into other forms of vitamin A, used during development of the chick or broken down.

I thank Mr C. M. Ward for technical assistance, and Dr M. E. Coates, Mr G. F. Harrison, MPS, and the staff of the henhouse, Nutrition Department, National Institute for Research in Dairying, for their co-operation.

\section{REFERENCES}

Neff, A. W., Parrish, D. B., Hughes, J. S. \& Payne, L. F. (1949). Arch. Biochem. $21,315$. Parrish, D. B., Williams, R. N., Hughes, J. S. \& Payne, L. F. (1950). Arch. Biochem. 29, I. Parrish, D. B., Williams, R. N. \& Sanford, P. E. (1951). Arch. Biochem. Biophys. 34, 64.

Plack, P. A. (1960). Nature, Lond., x86, 234.

Plack, P. A. (1963). Brit. F. Nutr. 17, 235.

Plack, P. A. \& Kon, S. K. (196r). Biochem. F. 81, 56r.

Plack, P. A., Woodhead, A. D. \& Woodhead, P. M. J. (196r). F. mar. biol. Ass. U.K. 4I, 617. 